\title{
Sulfuric Acid Leaching of Cobalt-Rich Ferromanganese Crust using Sodium Sulfite and Hydrogen Peroxide as Reducing Agents
}

\author{
Junji SHIBATA, Takashi WATARI and Masakazu NIINAE
}

\begin{abstract}
Sulfuric acid leaching of $\mathrm{Co}, \mathrm{Ni}, \mathrm{Cu}, \mathrm{Mn}$ and $\mathrm{Fe}$ from cobalt-rich ferromanganese crust under reducing conditions was performed using sodium sulfite and hydrogen peroxide as reducing agents.

High extraction of $\mathrm{Co}, \mathrm{Mn}$ and $\mathrm{Fe}$ could not be obtained by only sulfuric acid without reducing agents. Meanwhile, the high extraction of $\mathrm{Cu}$ could be obtained by only sulfuric acid without reducing agents and the high extraction of $\mathrm{Ni}$ could be obtained at the leaching temperature above $70^{\circ} \mathrm{C}$. When sodium sulfite and hydrogen peroxide were used as reducing agents, the high extraction of $\mathrm{Co}, \mathrm{Ni}, \mathrm{Cu}$ and $\mathrm{Mn}$ could be obtained. In particular, when hydrogen peroxide was used as reducing agent, the metals could be extracted with stoichiometric amount of hydrogen peroxide.
\end{abstract}

\section{1. 緒言}

マソガンノジュールおよびュバルトリッチクラスト は,コバルト，ニッケルおよび銅など有価金属の潜在資 源として広く知られている。コバルトリッチクラストの コバルト含有率は, マンガンノジュールと比べて高いこ とから，特にコバルト資源として期待されている。また， マンガンノジュールが 4,000〜6,000 m の深海底に広く 分布しているのに比べ，コバルトリッチクラストは $800 \sim 2,400 \mathrm{~m}$ と比較的浅い領域に分布するらえに日本 の経済水域内でも発見されていることから，わが国に拉 いてもその処理方法を早急に確立する必要がある。しか し、コバルトリッチクラストの製錬法の開発研究は，そ の発見がマンガンノジュールと比べて新しいことるあ り，その報告例は少ない1 6)。

本研究では, 過酸化水素および亜硫酸ナトリウムを還 元剤としたコバルトリッチクラストの硫酸浸出を行い,

\footnotetext{
* 関西大学工学部化学工学科

** 京都大学工学研究科資源工学専攻 平成10年 2 月 13 日受理
}

各種金属の浸出性について検討を行ったので，その結果 について報告する。

\section{2. 実 験 方 法}

\section{1 試料}

実験に使用したコバルトリッチクラスト（以後, Co クラストと呼ぶ）は，グアム島北東沖合で採取されたも ので, 一週間以上風乾した後, 粗砕し, 黒色部と茶褐色 の基盤部を手選で取り分けた後，黒色のクラスト部のみ を $74 \mu \mathrm{m}$ 以下に粉砕し, 密閉容器に保存したものを浸 出実験に供した。実験に使用した Co クラストの化学分 析値を Table 1 に示す。ぬた, クラスト部の真比重およ び見かけ比重は各々2.8および1.9であった。また，BET 法により比表面積を測定した結果，比表面積は約 $140 \mathrm{~m}$ $2 / \mathrm{g}$ と大きな值を示した。また，細孔径分布は $2 \mathrm{~nm} に$ 集中していた。クラスト部について X 線回折を行った が，明確な回折ピークが得られず，構成成分の同定はで きなかった。ただし，基盤部は $\mathrm{X}$ 線回折よりリン灰石 (Fluorapatite) であることが確認された。 
Table 1 Chemical analysis of cobalt-rich ferromanganese crust

\begin{tabular}{l|ccccc}
\hline Element & $\mathrm{Co}$ & $\mathrm{Ni}$ & $\mathrm{Cu}$ & $\mathrm{Mn}$ & $\mathrm{Fe}$ \\
\hline Content (wt\%) & 0.44 & 0.33 & 0.12 & 15.1 & 12.1 \\
\hline
\end{tabular}

\section{2 浸出実験}

浸出実験は, 温度計, 冷却管, 擋拌翼を取り付けた容 量 $300 \mathrm{~cm}^{3}$ の丸底フラスコに所定濃度の硫酸溶液 200 $\mathrm{cm}^{3}$ を入れ，恒温水槽内に固定し，所定温度になるまて 保持した後, Co クラスト $2 \mathrm{~g}$, 所定量の還元剤を添加 し漫出を行った。擋拌速度は $400 \mathrm{rpm}$ 一定とした。所 定時間ごとに浸出液を分取し，浸出液中の金属濃度を原 子吸光分光光度計（侏立製作所製 Z-6000）で定量し た。浸出率は [(浸出液中の金属成分量) / (試料中の 金属成分量) $] \times 100(\%)$ によ求めた。

\section{3. 実験結累および考察}

\section{1 還元剤を用いない場合}

Fig. 1 に, 硫酸濃度 $1.5 \mathrm{~mol} / \mathrm{dm}^{3}$, 浸出温度 $30^{\circ} \mathrm{C}$ に 扣ける金属の浸出率と浸出時間の関係を示す。 $\mathrm{Cu}$ の浸 出率は浸出時間 $30 \mathrm{~min}$ で $90 \%$ 以上の高い值を示すが， $\mathrm{Fe}$ および $\mathrm{Ni}$ は，浸出時間 $180 \mathrm{~min}$ 経過しても緩やか であるが増加傾向を示し，しかも各々の浸出率は約 $50 \%$ 扣よび約 $35 \%$ と低い值を示した。一方，Go 特よび Mn の浸出率は $5 \%$ 以下と低く，これは，硫酸には還元作用 がないため, 酸化マンガン (IV) の溶解反応が進まず,

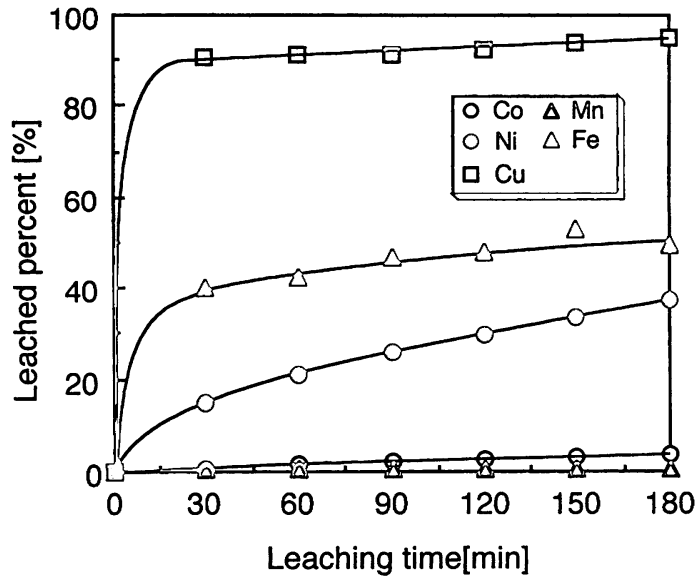

Fig. 1 Effect of leaching time on sulfuric acid leaching of metals.

$\mathrm{H}_{2} \mathrm{SO}_{4}$ concentration: $1.5 \mathrm{~mol} / \mathrm{dm}^{3}$

Leaching temperature: $30^{\circ} \mathrm{C}$

Pulp density: $10 \mathrm{~g} / \mathrm{dm}^{3}$
高志・新苗 正和

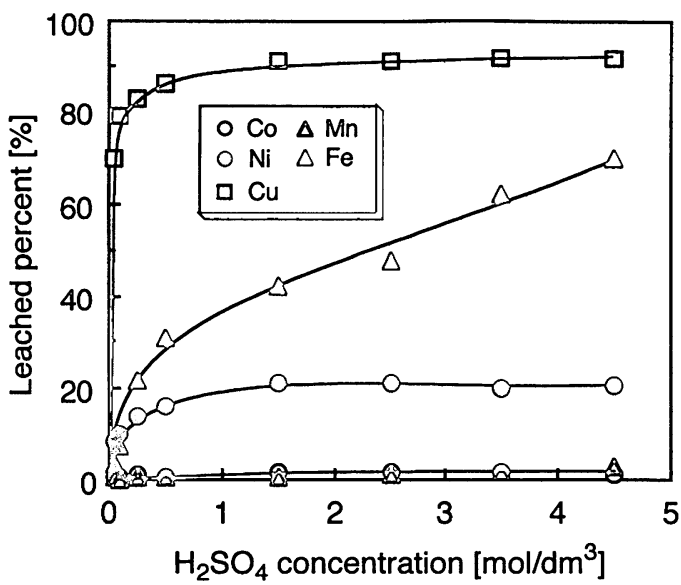

Fig. 2 Effect of sulfuric acid concentration on leaching of metals.

Leaching temperature: $30^{\circ} \mathrm{C}$

Leaching time: $60 \mathrm{~min}$

Pulp density: $10 \mathrm{~g} / \mathrm{dm}^{3}$

酸化マンガン (IV) 相内に存在するコバルトの浸出が進 行しないためと考觉られる。

次に, 浸出温度 $30^{\circ} \mathrm{C}$, 浸出時間 $60 \mathrm{~min}$ に打いて, 金属の浸出率に与える硫酸濃度の影響を検討した。その 結果を Fig. 2 に示す。 $\mathrm{Cu}$ の浸出率は, 硫酸濃度 0.25 $\mathrm{mol} / \mathrm{dm}^{3}$ でも $80 \%$ 以上の高い浸出率を示すが，Co およ び Mn は硫酸濃度を高くしても $3 \%$ 以下の浸出率しか 得られなかった。一方, Fe の浸出率は他の金属と比べ て硫酸濃度に大きく依存し, 硫酸濃度の増加とともに大

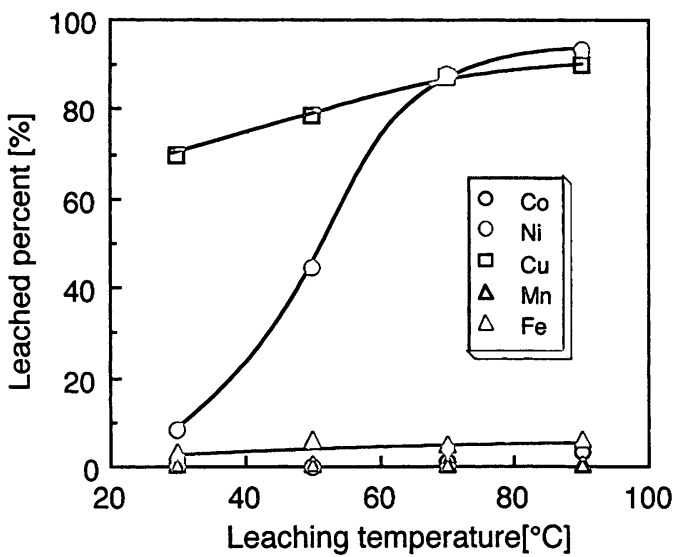

Fig. 3 Effect of leaching temperature on sulfuric acid leaching of metals.

$\mathrm{H}_{2} \mathrm{SO}_{4}$ concentration: $0.05 \mathrm{~mol} / \mathrm{dm}^{3}$

Leaching time: $60 \mathrm{~min}$

Pulp density: $10 \mathrm{~g} / \mathrm{dm}^{3}$ 
きく浸出率が増加している。

Fig. 3 K, 硫酸濃度 $0.05 \mathrm{~mol} / \mathrm{dm}^{3}$, 浸出時間 $60 \mathrm{~min}$ に扣ける金属の浸出率と浸出温度の関係を示す。 $\mathrm{Ni}$ の 浸出率は, 浸出温度の増加とともに急激に増加するが, それ以外の金属の浸出率は, $\mathrm{Cu}$ でわずかに増加傾向が 見られる程度で, $\mathrm{Co}, \mathrm{Mn}$ および $\mathrm{Fe}$ には大きな変化は 見られず，この硫酸濃度では低い值を示した。Cuの浸 出率は， $70^{\circ} \mathrm{C}$ でほぼ100\%の浸出率が得られた。

以上の検討から，硫酸のみによる浸出では $\mathrm{Ni}$ 扎よび $\mathrm{Cu}$ 以外の金属成分の浸出は困難であることが分かる。

\section{2 還元剤として亜硫酸ナトリウムを用いた場合}

Go クラストの主成分である Mn は，マンガンノジ ュールと同様に酸化マンガン (IV) であると考えられて いる7,8)。したがって，還元剤として亜硫酸ナトリウム を用いることにより，酸化マンガン (IV) 相を破壊する ことができれば，その中に含まれると考劣られる Co の 高い浸出率が得られることが期待できる。還元剤として 亜硫酸ナトリウムを用いた場合, 浸出時間 $60 \mathrm{~min}$ 以内 でいずれの金属も浸出平衡に達することが実験で確認で きた。そこで, 亜硫酸ナトリウム濃度 $0.0317 \mathrm{~mol} / \mathrm{dm}^{3}$, 浸出温度 $30^{\circ} \mathrm{C}$, 浸出時間 $60 \mathrm{~min}$ において, 金属の浸 出率に与える硫酸濃度の影響を検討した。その結果を Fig. 4 亿示す。硫酸濃度 $0.005 \mathrm{~mol} / \mathrm{dm}^{3}$ ではいずれの金 属も浸出しない。硫酸濃度 $0.03 \mathrm{~mol} / \mathrm{dm}^{3}$ では $\mathrm{Co}, \mathrm{Ni}$ および Mn が17\%〜 40\%程度浸出し， Cu および Fe に ついては全く浸出が見られない。これは最終 $\mathrm{pH}$ が4 以上と高いことから，Fe (III) は水酸化物として沈殿し， $\mathrm{Cu}$ については Fe (III) 水酸化物と共沈するためと考光

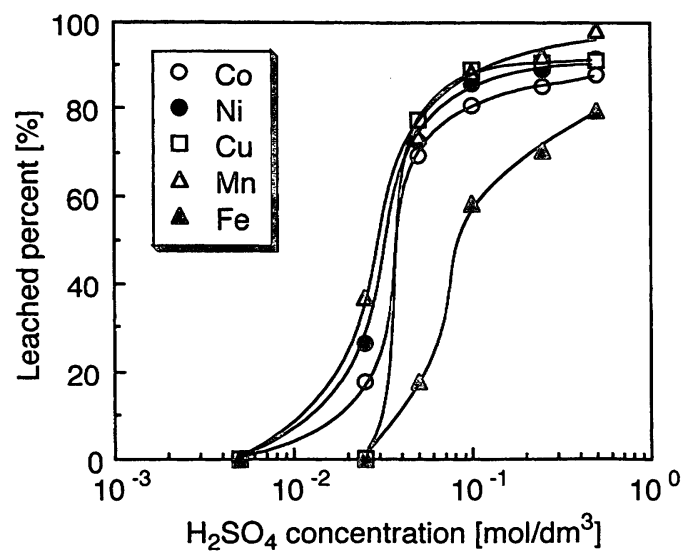

Fig. 4 Effect of sulfuric acid concentration on leaching of metals.

$\mathrm{Na}_{2} \mathrm{SO}_{3}$ concentration: $0.0317 \mathrm{~mol} / \mathrm{dm}^{3}$

Leaching temperature: $30^{\circ} \mathrm{C}$

Leaching time: $60 \mathrm{~min}$

Pulp density: $10 \mathrm{~g} / \mathrm{dm}^{3}$
られる。硫酸濃度 $0.03 \mathrm{~mol} / \mathrm{dm}^{3}$ 以上でいずれの金属の 浸出率も急激に増加する。

次に，浸出率に与える亜硫酸ナトリウム濃度の影響に ついて検討を行った。Fig. 5 は, 硫酸濃度 $0.1 \mathrm{~mol} / \mathrm{dm}^{3}$, 浸出温度 $30^{\circ} \mathrm{C}$, 浸出時間 $60 \mathrm{~min}$ に打ける, 各金属成 分の浸出率と亜硫酸ナトリウム濃度の関係を示す。 $\mathrm{Ni}$ だけでなく硫酸のみではほとんど浸出されなかった Co および Mnの浸出率が，亜硫酸ナトリウム濃度の増加 とともに顕著に増大し, 亜硫酸ナトリウム濃度 0.04 $\mathrm{mol} / \mathrm{dm}^{3}$ でほぼ $100 \%$ の浸出率が得られた。これは Co クラストの主成分である酸化マンガン (IV) 相を亜硫酸 ナトリウムが還元破壊することを如実に示している。一 方, $\mathrm{Fe}$ の浸出率は, 亜硫酸ナトリウム濃度の増加とと もに大きく増加するが, 亜硫酸ナトリウム濃度 0.04 $\mathrm{mol} / \mathrm{dm}^{3}$ 以上では約 $70 \%$ で一定となった。

Fig. 6 は, 硫酸濃度 $1.0 \mathrm{~mol} / \mathrm{dm}^{3}$, 亜硫酸ナトリウム 濃度 $0.0119 \mathrm{~mol} / \mathrm{dm}^{3}$, 浸出時間 $60 \mathrm{~min}$ に特ける金属の 浸出率と浸出温度の関係を示す。浸出温度の増加ととも に $\mathrm{Fe}$ と $\mathrm{Ni}$ の浸出率は大きく増加するが，それ以外の 金属では，浸出率に大きな変化は見られない。

\section{3 還元剤として過酸化水素を用いた場合}

過酸化水素は, 通常酸化剂として用いられるが, 酸化 作用と還元作用の両方を有し, 酸化マンガン (IV) など の強酸化性物質と共存すると還元風として作用する。還 元剤として過酸化水素を用いた場合, 浸出時間 $30 \mathrm{~min}$ 以内でいずれの金属成分も浸出平衡に達することが実験 で確認できた。そこで, 過酸化水素が金属の浸出性に与 える影響について検討した。Fig. 7 は, 硫酸濃度 0.05 $\mathrm{mol} / \mathrm{dm}^{3}$, 浸出温度 $30^{\circ} \mathrm{C}$ 牤よび浸出時間 $60 \mathrm{~min}$ に拉

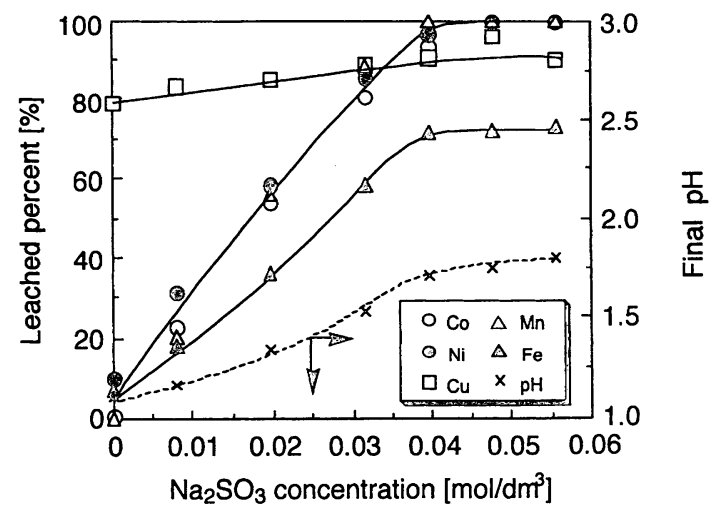

Fig. 5 Effect of sodium sulphite concentration on sulfuric acid leaching of metals.

$\mathrm{H}_{2} \mathrm{SO}_{4}$ concentration: $0.1 \mathrm{~mol} / \mathrm{dm}^{3}$ Leaching temperature: $30^{\circ} \mathrm{C}$

Leaching time: $60 \mathrm{~min}$ Pulp density: $10 \mathrm{~g} / \mathrm{dm}^{3}$ 


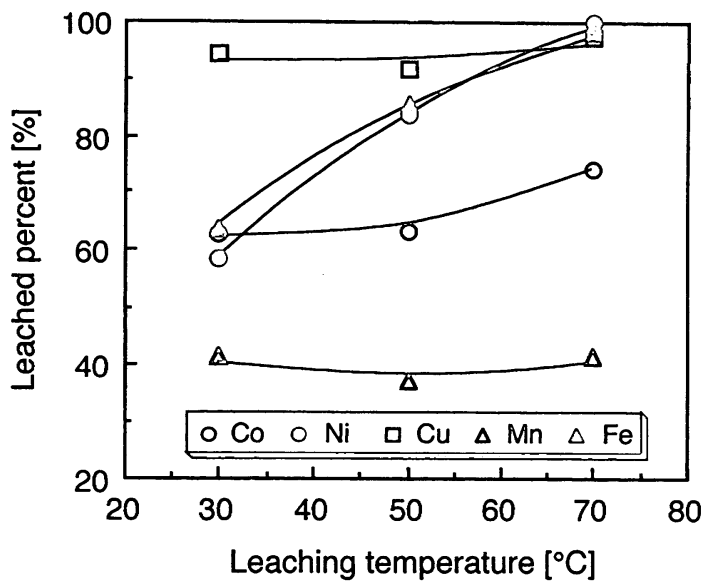

Fig. 6 Effect of leaching temperature on sulfuric acid leaching of metals in the presence of sodium sulfite.

$\mathrm{Na}_{2} \mathrm{SO}_{3}$ concentration: $0.0119 \mathrm{~mol} / \mathrm{dm}^{3}$

$\mathrm{H}_{2} \mathrm{SO}_{4}$ concentration: $1.0 \mathrm{~mol} / \mathrm{dm}^{3}$

Leaching time: $60 \mathrm{~min}$

Pulp density: $10 \mathrm{~g} / \mathrm{dm}^{3}$

いて，金属の浸出率と過酸化水素濃度の関係を示したも のである。亜硫酸ナトリウムの場合と同様に，硫酸のみ ではほとんど浸出されなかった Co および Mn の浸出 率が，過酸化水素濃度の増加とともに著しく増加してい る。また，Fe の浸出率が低く抑兄られ，しかも過酸化 水素濃度 $0.015 \mathrm{~mol} / \mathrm{dm}^{3}$ 以上で減少傾向を示すのは, 浸 出液の $\mathrm{pH}$ の増加により, $\mathrm{Fe}$ (III) が一部水酸化物とし て沈殿するためと考兄られる。

\section{4 化学量論的考察}

Co クラスト中の各金属成分の形態については, $\mathrm{X}$ 線 回折からは同定できなかったが，Co クラストの主成分 である Mn はマンガンノジュールと同様に酸化マンガ ソ (IV) として存在すると言われている。したがって， 亜硫酸ナトリウムを用いた場合，硫酸溶液中では次のよ らな酸化マンガン (IV) の浸出反応が考学られる。

$$
\begin{aligned}
& \mathrm{MnO}_{2}+\mathrm{Na}_{2} \mathrm{SO}_{3}+\mathrm{H}_{2} \mathrm{SO}_{4} \\
& \quad=\mathrm{MnSO}_{4}+\mathrm{Na}_{2} \mathrm{SO}_{4}+\mathrm{H}_{2} \mathrm{O}
\end{aligned}
$$

パルプ濃度 $10 \mathrm{~g} / \mathrm{dm}^{3}$ で浸出を行った場合, 酸化マン ガン (IV) を完全に浸出するには，(1) 式より化学量論 的に約 $0.028 \mathrm{~mol} / \mathrm{dm}^{3}$ の亜硫酸ナトリウムが必要であ る。しかし，先に示した Fig. 5 を見ると，亜硫酸ナト リウムの化学量論的必要量 $0.028 \mathrm{~mol} / \mathrm{dm}^{3}$ を越えても $\mathrm{Mn}$ の浸出率は大きく増加している。このことは, 亜硫 酸ナトリウムを用いる場合，高い浸出率を得るには，理 論量より過剰の亜硫酸ナトリウムを必要とすることを示 している。
高志・新苗 正和

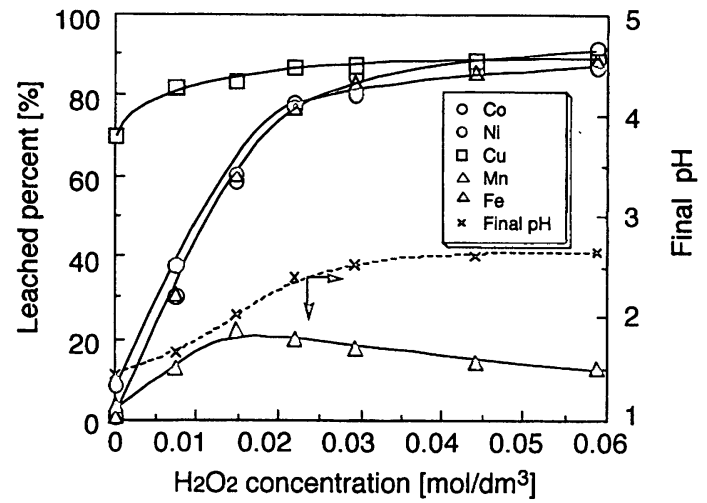

Fig. 7 Effect of hydrogen peroxide concentraion on sulfuric acid leaching of metals.

$\mathrm{H}_{2} \mathrm{SO}_{4}$ concentration: $0.05 \mathrm{~mol} / \mathrm{dm}^{3}$

Leaching temperature: $30^{\circ} \mathrm{C}$

Leaching time: $60 \mathrm{~min}$

Pulp density: $10 \mathrm{~g} / \mathrm{dm}^{3}$

一方，過酸化水素を用いた場合，硫酸溶夜中では次の よらな酸化マンガン (IV) の浸出反応が考兄られる。

$$
\begin{aligned}
& \mathrm{MnO}_{2}+\mathrm{H}_{2} \mathrm{O}_{2}+\mathrm{H}_{2} \mathrm{SO}_{4} \\
& =\mathrm{MnSO}_{4}+2 \mathrm{H}_{2} \mathrm{O}+\mathrm{O}_{2}
\end{aligned}
$$

パルプ濃度 $10 \mathrm{~g} / \mathrm{dm}^{3}$ で浸出を行った場合，(2) 式より 酸化マンガン (IV) を完全に浸出するには，亜硫酸ナト リウムと同様に, 化学量論的には約 $0.028 \mathrm{~mol} / \mathrm{dm}^{3}$ の過 酸化水素を必要とする。先に示した Fig. 7 亿执いて, $\mathrm{Mn}$ の浸出率は, 過酸化水素濃度 $0.028 \mathrm{~mol} / \mathrm{dm}^{3}$ で高い 值を示し，しかもそれ以上では注とんど浸出率に変化は 見られない。このことから過酸化水素を用いる場合，化 学量論的にほ医理論量で目的金属成分を浸出できること が分かる。

\section{4. 結}

論

亜硫酸ナトリウムおよび過酸化水素を還元剤として用 いた硫酸溶液によるコバルトリッチクラストの浸出を行 い, $\mathrm{Co}, \mathrm{Ni}, \mathrm{Cu}, \mathrm{Mn}$ および $\mathrm{Fe}$ の浸出について検討し， 以下の結論を得た。

1) Go は主に酸化マンガン (IV) 相に存在すると考 学られ，還元剤を用いない硫酸のみによる浸出では高い 浸出率を得ることはできなかった。一方， Cu の浸出率 は硫酸のみで高い值が得られ，また，Ni とついては， 浸出温度を $70^{\circ} \mathrm{C}$ 以上にすることにより高い浸出率を得 ることができた。

2 ）還元剤として亜硫酸ナトリウムおよび過酸化水素 を用いた場合，硫酸のみでは低い浸出率しか得られない 低濃度の硫酸溶液でも，Co および Ni の高い浸出率が 
得られた。特に, 過酸化水素を用いた場合, 酸化マンカ ン (IV) と化学量論的に反応し, 必要最小限の濃度で Co および Ni を浸出することが可能であった。

\section{謝辞}

本研究を遂行するに当たり，実験用試料として貴重な コバルトリッチクラストを提供していただいた金属鉱業 事業団の関係者に深く感謝の意を表します。

\section{参 考 文献}

1）藤井雄二郎, 溝田忠人, 河野好美: 海洋科学, Vol. 19, No. 4, pp. 245-252 (1987)

2) J. P. Allen, H. L. Abercrombic and D. A. Rice:
Miner. \& Metall. Process., May, pp. 97-104 (1991)

3）六川暢了：資源と素材，Vol. 108，No. 3，pp. 187-191 (1992)

4) M. Niinae, N. Komatsu, Y. Nakahiro, T. Wakamatsu and J. Shibata: Hydrometallurgy, Vol. 40, Nos. 1-2, pp. 111-121 (1996)

5）新苗正和, 三浪純子, 朴 賛而, 中廣吉孝 : 資源処 理技術, Vol. 43, No. 3, pp. 115-121 (1996)

6）井上 章, 河原正泰: 資源と素材, Vol. 112, No. 13, pp. 947-951 (1996)

7) 白井 朗, 寺島 滋, 湯浅真人: 海洋科学, Vol. 19, No. 4, pp. 215-220 (1987)

8) B. W. Haynes and M. J. Magyear: Marine Minerals, pp. 235-246 (1987) 